\title{
'Is climate science taking over the science?': A corpus-based study of competing stances on bias, dogma and expertise in the blogosphere
}

\author{
Luis Pérez-González (iD ${ }^{1 凶}$
}

Climate change science has become an increasingly polarized site of controversy, where discussions on epistemological rigour are difficult to separate from debates on the impact that economic and political interests have on the production of evidence and the construction of knowledge. Little research has been conducted so far on the antagonistic discursive processes through which climate knowledge is being contested and traditional forms of expertise are being (de-)legitimized-whether by members of the scientific community or non-scientist actors. This corpus-based study contributes to previous scholarship on the climate science controversy in a number of respects. Unlike earlier studies based on the analysis of mainstream media articles, this paper interrogates a corpus of climate change blog posts published by scientists, journalists, researchers and lobbyists laying claim to core, contributory and interactional forms of expertise-as conceptualized within the third wave of science studies. Further, the corpus informing this study has been designed to reflect the complex and multivoiced nature of the climate knowledge production process. Drawn from five different blogs, the views represented are not confined to the two poles between which the entrenched dialectic of 'alarmists' versus 'deniers' is typically played out in the climate science debate. Following a systemic functional conceptualization of dialogic engagement as a means of positioning authorial voices vis-à-vis competing perspectives construed and referenced in a text, this paper reports on bloggers' use of three lexical items (bias, dogma and peer review) to expose their reliance on (non-)epistemic values. Concordances and a range of visualization tools are used to gain systematic insights into the network of lexical choices that obtain around these items, and to gauge whether/how bloggers construct coherent authorial subjectivities in a bid to claim expert status and/or question the recognition of other players in the debate.

\footnotetext{
${ }^{1}$ Centre for Translation and Intercultural Studies, University of Manchester, Manchester, UK. ${ }^{凶}$ email: Luis.Perez-Gonzalez@manchester.ac.uk
} 


\section{Introduction}

he Genealogies of Knowledge Internet corpus is a collection of English texts published in a range of online news outlets and blogs written by journalists, academics and activists situated mainly on the radical right and left of the political spectrum. The Internet corpus features texts where these engaged online actors challenge and redefine key cultural concepts pertaining to the body politic, whether along populist or prefigurative lines; alongside this material, it also holds a body of texts problematizing concepts that underpin established scientific discourses and the role they currently play in the construction and circulation of knowledge. ${ }^{1}$ Among the outlets included in the latter group, this study focuses on climate change blogs, conceptualized here as increasingly politicized and polarized sites of controversy, where epistemological discussions on the quality of the science are difficult to separate from questions of scientific knowledge construction. Whether by raising suspicions of established forms of expertise, advocating new epistemic frameworks of environmental governance, or even denouncing governments' interference with the work of scientists employed by public bodies, this collection of texts exposes forms of contestation against "power at its extremities, in its ultimate destinations ... where it becomes capillary" (Foucault, 1980, p. 96). Exercising these forms of resistance through blogs favours the emergence of local communities of social practice as alternative regimes of expertise governance and knowledge construction-often outside the control of national and supranational structures of political and/or corporate power.

Over the last decade, a growing body of research within the field of science communication has investigated how media shape public perceptions of the impact of anthropogenic climate change and facilitate the "transitioning from [public] awareness and concern to action" (Moser, 2016, p. 345). Studies gauging the impact of media coverage on the public understanding of climate change (e.g. Feldman et al., 2015; Brevini and Lewis, 2018) have explored how political, corporate or consumerist discourses are contesting the weight of evidence about the causes and consequences of this phenomenon in the public arena; recent research has also revealed the extent to which collective perceptions of climate change reflect the considerable ground that political actors have gained vis-à-vis their scientific counterparts in climate news coverage over the last three decades (Chinn et al., 2020). As digital media outlets continue to increase the public's exposure to a widening range of competing climate change discourses animated by an ever more varied array of participants and stakeholders, the reasons why individuals "choose news outlets where they expect to find culturally congruent arguments about climate change" that are consistent with their "cultural way of life" (Newman et al., 2018, p. 985) are becoming an object of increasing research interest.

The discursive frames, narratives and metaphors used by the media to represent climate change knowledge have also been studied by linguists seeking to gain a better understanding of their impact on people's "understanding of the phenomenon, their perception of the risks involved, the value judgements they make, and the emotional reactions they experience" (Fløttum, 2017, p.1). Among these language-centred approaches to the study of the climate change debate, corpus-based analyses have offered useful quantitative insights into various aspects of this site of knowledge production. Dayrell and Urry (2015) draw on a large Brazilian Corpus on Climate Change to test the hypothesis that Brazilian news media take and promote "a consensus or gradualist view of climate change" $(2015$, p. 265$)$ that leaves very little room for sceptical voices. By quantifying the occurrence of key lexical items (including names of selected organizations, scientists and public figures aligned with the consensus view), they demonstrate that gradualism ${ }^{2}$ prevails over climate change scepticism in Brazilian media discourses. Similarly, a corpus of Brazilian daily newspaper articles extracted from the news aggregator service Factiva informs Dayrell's (2019) study of the evolution of Brazilian media's climate discourses over a 10 -year period. After measuring the distribution of a selection of key lexical items and phrases such as 'mudança climática' and 'emissões de carbono' and their respective collocates across time, Dayrell interprets the findings against a range of opinion polls on public perceptions of climate change. Her analysis reveals how Brazilian media discourses have shifted over time, "engendering a striking level of climate change concern" (2019, p. 164) and "encouraging engagement with the debate, especially in relation to deforestation" (2019, p. 167). Beyond these corpus-based studies of mainstream media discourses, researchers have turned to corpora of other types of textual material-including social media feeds (Schäfer, 2012; Auer et al., 2014; O’Neill et al., 2015) and blogs (Salway et al., 2016; Salway, 2017) — to conduct automatic text analyses. Salway's grammar induction algorithm, a new technique for elucidating linguistic patterning, "induces salient information structures from unannotated corpora" (2017, p. 161) to highlight discursive features of individual blogs using statistical rather than linguistic information.

The present study also adopts a corpus-based methodology but, unlike earlier analyses of corpora holding mainstream media articles, it interrogates a collection of posts on climate change drawn from five blogs, i.e. a subset of the Genealogies of Knowledge Internet corpus referred to in this article as the Climate Science Blogger Corpus (CSBC). ${ }^{3}$ In focusing on blogs, this paper also intersects with a fast developing body of scholarship within the wider field of science communication that investigates climate change debates held in online public arenas between scientific expert bloggers and their readers (Lörcher and Taddicken, 2017); and explores how commenters on controversial science blogs are consolidating increasingly polarized publics, rather than fostering a more deliberative engagement across mutually opposing constituencies (Metcalfe, 2020). In order to facilitate the study of the multivoiced debate on climate science, CSBC features material written from a range of competing perspectives, not confined to the two poles between which the entrenched dialectic between 'alarmists' and 'deniers' is played out (Howarth and Sharman, 2015). This compilation of posts published by scientists, journalists, researchers and lobbyists therefore seeks to represent the views through which various individuals and organizations lay claim to traditionally sanctioned forms of expertise, purport to possess alternative forms of expertise, and narrate others' perspectives as belonging to the realm of pseudoscience. By foregrounding the range of experiences and narratives voiced in this selection of blog posts, CSBC provides an optimal vantage point to observe how climate science knowledge, where science is pitted against science, is fought in the public arena.

After outlining a series of developments that have warranted the characterization of climate science as a site of controversy (section "Climate science as a site of controversy"), this paper draws on disciplinary insights from the field of expertise and experience studies to gain a better understanding of ongoing negotiations of expertise in the climate science blogosphere (section "Negotiating contrasting certainties in the climate science blogosphere"). While previous waves of science studies, notably the sociology of scientific knowledge, have contributed to democratizing science by extending participation in technical decision-making beyond the control of accredited scientists, studies of expertise and experience set out to widen expert debate without diluting the notion of technical expertise by including the general public. Under this framework, the negotiation of 
contrasting certainties in the climate science blogosphere is accounted for in terms of a struggle between different forms of expertise and the dialectic between the epistemic and nonepistemic values embraced by different expert constituencies in the public debate. As this paper is primarily interested in revealing how bloggers engage with alternative stances construed as competing or complementary in the climate science debate, the final part of section "Negotiating contrasting certainties in the climate science blogosphere" explains how Martin and White's (2005) notion of 'engagement' informs the analysis of online debates in this alternative network of scientific knowledge production. After providing a full description of the composition of the Climate Science Blogger Corpus in section "Investigating bloggers' stances: Data and conceptual framework", section “Analysing CSBC bloggers' construction of intersubjectivity: Bias, dogma, peer review" makes use of a concordance browser and a suite of visualization tools developed as part of the Genealogies of Knowledge project to produce both quantitative and qualitative insights into the language deployed by different actors in the climate change debate. Ultimately, in keeping with the wider research agenda of the Genealogies of Knowledge project, of which contestation of established knowledge is a main strand, the aim is to investigate the construction of intersubjectivity through which actors claim expert status and/or question the recognition of other players in the debate.

\section{Climate science as a site of controversy}

Since 1998, the assessment of the growing evidence base available on the impact of anthropogenic climate change has been entrusted to the Intergovernmental Panel on Climate Change (IPCC), a United Nations body tasked with scrutinizing published research to "identify where there is agreement in the science community" (IPCC, n.d.). The panel's reports translate scientific evidence into "policy-relevant but not policy-prescriptive" recommendations (IPCC, n.d.) for member governments, effectively providing an internationally accepted authority on climate change. But while a commitment to objectivity and neutrality underpins IPCC's "adaptation and mitigation" proposals (IPCC, n.d.), the "entanglement of cultural meanings and policy-relevant facts" (Kahan et al., 2017, p. 79) that frames the climate science debate has unleashed a growing partisan polarization both among political elites and the public (Beck et al., 2014). In this context, the recommendations issued by IPCC in 2016 to professionalize its communication strategies and enhance the readability of its official reports as a way of reinforcing the trustworthiness of climate science (Hulme, 2017) have failed to effect meaningful change. With the politicization of climate science and environmental governance continuing to rise unabated (Carrozza, 2015), even compelling evidence endorsed by IPCC reports is routinely challenged in the public arena, as new agents become involved in the production of climate knowledge and "more convoluted routes to the construction of facts" gain traction (Epstein, 1995, p. 411).

Since it made its appearance in the early 1970s, the sociology of scientific knowledge (SSK) - also known as the second wave of science studies-has paid much closer attention to issues of legitimacy, participation and transparency in the context of evidence-based environmental policy-making. Notably, SSK advocates an epistemic shift towards social constructivism, understood as "the study of how complex scientific claims and technological products are put together out of heterogeneous construction materials" (Jasanoff, 1999, p. 66). From a SSK perspective, science-based decisions should not be driven only by scientific practices that sever evidence from the social environment in which credentialed scientists are embedded (Jasanoff,
2010, p. 235). Indeed, as is generally acknowleged, policy-making involves "many steps, including devising the policy as an executable plan, involving administration and implementation, goals and values, and interests that are benefitted or harmed" (Turner, 2014 , p. 4). This constructivist turn in science studies and the reconceptualization of climate science as a social activity that it entails represent a major departure from mid-20th century sociology of science, which postulated that "sociological accounting had to stop at the door of scientific method and scientific knowledge" (Shapin, 1995, pp. 294-295) and propped up an information deficit or linear model approach to science communication (Jasanoff and Wynne, 1998). Instead, SSK empowers citizens and stakeholders with relevant experience to become involved in decision-making where science intersects with the political domain (Wynne, 1989). By blurring the distinction between science and society and acknowledging the central role that social judgements play in environmental governance, SSK brings into sharp relief the constitutive role of citizen participation in the production of scientific evidence. This process of democratization ultimately seeks to enable a more productive dialectic between the "larger scales of scientific representations" and "smaller scales of social meaning" (Jasanoff, 2010 , p. 238), and to recognize the contribution and "value of local, indigenous, or other experiential knowledge" (Collins and Evans, 2020, p. 86).

The insight that climate science reflects the struggle between science and democracy at the point where evidence is brought to bear on policy decisions and governance is particularly pertinent in digital media culture-where the blogs posts held in CSBC originate. Under the knowledge aggregation logic that prevails in the networked public sphere, "a more connected, science-aware (and often sceptical) public" (Gluckman, 2014) is capitalizing on the affordances of digital technology to lay a claim to various causes and asking more challenging questions from scientists and decision-makers around issues that "involve significant valuesbased judgements" (Gluckman, 2014). But while the construtivist turn has set out a clear rationale to recognize the grounded types of evidence provided by non-scientists and the challenge that experience poses to credentialed expertise, SSK's conceptualization of expertise is not nuanced enough to inform an analysis of how contrasting certainties are negotiated in the climate science blogosphere. Ultimately, the sociology of scientific knowledge falls short of explaining "what expertise consists of, the kinds of decisions for which it is relevant" (Collins and Evans, 2020, p. 89) and "the reason for using the advice of scientists and technologists in virtue of the things they do as scientists and technologists, rather than as individuals or as members of certain institutions" (Collins and Evans, 2002, p. 236).

\section{Negotiating contrasting certainties in the climate science blogosphere}

The second wave of science studies and its push to democratize expertise by opening up the construction of scientific knowledge to a wider group of citizens aptly recognizes the social judgements that underpin scientific controversy and the extent to which the climate science blogosphere challenges technocratic decisionmaking by consensus scientists. However, the logic behind the emergence of the constructivist approach can hardly be extended to account for a significant development in the vibrant Anglophone climate crisis blogosphere. The growing participation of members of the scientific community in blogged debates with non-scientists (Sharman, 2015) can be more productively regarded as a reaction against a loose understanding of the 'citizen scientist' notion and, more widely, as an attempt to "draw a boundary around the body of 'technically qualified-by-experience' 
contributors to technical decision-making" (Collins and Evans, 2002, p. 237). With Anglophone mainstream media often giving sceptical voices more prominent coverage than would be warranted by the weight of the evidence supporting their claims, blogs provide scientists with an opportunity to retain control over the knowledge circulating in the public arena (Poliakoff and Webb, 2007). Significantly, scientists' active engagement in public debate through blogging (Nisbet and Markowitz, 2015) has also been fostered by instances of Governmental meddling in the work of credentialed experts. Under George W. Bush's administration, for example, "political appointees and staffers were accused of improperly editing and censoring scientific agency reports; controlling the public and media statements of government scientists; and manipulating the use of scientific expertise and evidence" (Nisbet and Markowitz, 2015, p. 136). The widely held perception by climate scientists, among other experts, that the White House was tampering with their work to strengthen the administration's anti-regulatory stance on fossil fuel industries, and to cast doubt among the public about the credibility of climate science, significantly contributed to the emergence of a community of scientists who took to the blogosphere to advocate the virtues of the positivist scientific tradition. In doing so, they effectively chose to leave behind

traditional approaches to communication that emphasize the translation and dissemination of expert knowledge [and] are unlikely to reduce conflict and promote consensus. Simply focusing on the dissemination of scientific evidence tends to reinforce entrenched positions, since such evidence is often sufficiently tentative to indefinitely support the values-based arguments and worldviews of competing sides (Nisbet and Markowitz, 2015, p. 138).

Amid the growing enmeshment of politics with science, the adoption of a more adversarial stance to intervene in public debate is emerging as the preferred strategy by scientists involved in public outreach and dissemination activities, including but not limited to blogging ${ }^{4}$. As Oppenheimer et al. (2019) note, scientists used to favour univocality as a means to assert their epistemic dominance, even when this self-imposed demand for watertight professional consensus led them to downplay the likely effects of climate change in their exchanges with policy-makers and the public. However, as other actors have become involved in the construction of consensus and the management of knowledge disputes (Oppenheimer et al., 2019), differences of opinion-even within the scientific community-must now be actively exposed and debated.

The advent of the third wave of science studies-also referred to as studies of expertise and experience (SEE) - at the turn of this century provides a framework under which this development can be explored more productively. While accepting that policymaking in controversial domains of science should not be informed exclusively by formally accredited evidence, the proponents of SEE effectively query how far the right of 'experiencebased experts'-i.e. ordinary citizens in possession of grounded expertise-to participate in technical decision-making should extend (Collins and Evans, 2002). Under SEE, the analytical focus therefore shifts away from the construction of truth toward the acquisition and conceptualization of multiple forms of expertise. A 'realist model of expertise' is thus proposed to differentiate "the scientific and technical input to decisionmaking from the political input" (Collins and Evans, 2002, p. 249) in a bid to "explain what expertise consists of, the kinds of decisions for which it is relevant, and a way of telling who is and who is not an expert" (Collins and Evans, 2020, p. 89). ${ }^{5}$

The theory underpinning the third wave of science studies revolves around a categorization of expertise that was first outlined by Collins and Evans (2002) and then elaborated into a more detailed taxonomy presented as a 'periodic table of expertises' in Collins and Evans (2007, 2020). Under this taxonomy, 'specialist experts' in a given field, whether they are formally trained or not, are separated from non-specialists-a category comprised of certified scientists whose specialism lies in a different field and the lay public. Not only does this division avoid characterizing the scientific community as the sole possessor of technical expertise. Apart from acknowledging the socially and politically situated identity of scientists, it recognizes "the existence of pockets of expertise among the citizenry" (Collins and Evans, 2002, p. 249), regardless of whether such experience-based experts are credentialed or not. Ultimately, SEE's taxonomy of expertise tries to draw a clearer boundary around those individuals who can provide the best expert advice on a given issue, but without conflating technical knowledge and political rights.

Under SEE's taxonomy, the climate change blogosphere featured in CSBC can be seen as a site of struggle between competing forms of expertise. The 'core' set of experts in the field would consist of those scientists "who have actually done relevant experiments, or who have developed or worked with theories" pertaining to climate science (Collins and Evans, 2002, p. 260). Unlike members of the core set, experience-based bloggers (e.g. political lobbyists, journalists or specialists in other areas of science) strive to acquire various degrees of specialist expertise by immersing themselves in the climate change community. As Collins and Evans put it, "'[e]nculturation' is the only way to master an expertise which is deeply laden with tacit knowledge because it is only through common practice with others that the rules that cannot be written down can come to be understood" (2007, p. 24). From a SEE's perspective, those individuals who, through sustained enculturation, accrue enough expertise to contribute to climate science with sufficient competence are deemed to hold 'contributory expertise' (Collins and Evans, 2002, p. 254). Although there is a considerable overlap between the notions of core and contributory expertise (most individuals holding contributory expertise tend to be trained scientists), highly qualified experience-based experts can also acquire contributory expertise (Caudill et al., 2019, p. 6). By contrast, an individual with 'interactional expertise', the second variety mastered through immersion in a community of practice, "may be able to understand scientific things, and to discuss scientific things, but is still not able to do scientific things (Collins and Evans, 2007, p. 35; emphasis in original). In their most recent critique of these concepts, Collins and Evans (2020) reinforce their earlier view that all contributory experts are also interactional experts, but they also go on to claim that "it is possible to acquire interactional expertise to the level of that possessed by a contributory expert without mastering or even experiencing the physical practices that define the [relevant] domain of expertise" (Collins and Evans, 2020, p. 93).

The climate blogosphere can therefore be productively conceptualized as a 'trading zone' where questions over data, research priorities, participation and methodological approaches" (Jasanoff and Wynne, 1998, p. 61) have been negotiated among individuals holding a range of expertises for a number of decades. Throughout the 1990s, the uncertainties arising from their diverging perspectives on the 'co-production' (Jasanoff and Wynne, 1998), weighing and application of climate knowledge for the purposes of environmental governance were accounted for under the framework of 'post-normal science' (Funtowicz and Ravetz, 1991, 1992, 1993; Bremer et al., 2018). However, as the contributory and interactional forms of expertise of non-certified experts have become widely recognized under SSK and SSE, climate change science has thematized the legitimate role that experts' values play at various decision-points in the research 
process, from problem-selection to hypothesis choice (Douglas, 2009). The notions of '(non-)epistemic' or '(non-)cognitive values' that were once associated with the value-free ideal of science have been therefore superseded by an alternative classification under its value-laden counterpart. In their direct role, values act as the reasons why experts accept a given set of premises, draw upon a specific theory or declare that the evidence available to substantiate a claim is sufficient. By contrast, in their indirect role values are mobilized to manage uncertainty about the quantity or epistemic quality of the evidence available to experts, and to gauge the consequences of suboptimal decisions that may arise when uncertainty is present in the final stages of the research process (Douglas, 2009, p. 96). The implications of this focus on values for public perceptions of climate change have been laid bare in the work that Tangney $(2017,2019 a, 2019 b)$ has conducted from a policy-making perspective. Although the legitimate role of ethical and social values in the research process is now widely recognized, the fact that certain types of experts tend to rely exclusively on specific types of evidence and values can only serve to "inflame polarized climate change debate" and "identity-defining group commitments" (2019a, p. -s132). As Tangney notes, the clash between rhetorical policy-making tactics employed by competing expert constituencies driven by their preferred values has failed to "resolve environmental controversy and the pressing need for a pragmatic reframing of policy problems to allow for solutions based on bipartisan values" (Tangney, 2019a, p. 131).

This paper interrogates the CSBC corpus to study how bloggers holding competing views on climate change go about negotiating the intersubjective stance that they mobilize in their posts to claim relevant expertise and contest the voices of other actors in the debate. Adopting a SEE perspective that recognizes a legitimate role for core, contributory and interactional experts in the climate change debate, this CSBC-based study will analyse how the dialectic between evidence and values is mediated by bloggers holding varying forms of expertise; explore how bloggers attempt to (de-)legitimize other voices; and examine how alternative translations of evidence into policy are proposed and negotiated. Just as experience-based experts may feel that core experts overrely on epistemic values to "promote risk-based decision-making under erroneous ideals of linear-instrumental-rationality" (Tangney, 2019b, p. 1), credentialed experts will oppose 'politicized' science when non-epistemic values play an indirect role at early stages of the research process that should be informed exclusively by evidence (Douglas, 2009, pp. 112-113).

Among the various approaches that have been used by scholars in the past to investigate how writers express their "attitude or stance towards, viewpoint on, or feelings about the entities or propositions" that they write about (Thompson and Hunston, 2000 , p. 5), I draw on Martin and White's (2005) conceptualization of 'engagement', developed as part of their wider theory of the language of evaluation in English within the tradition of systemic functional linguistics. Concerned with the study of "sourcing attitudes and the play of voices around opinions in discourse" (Martin and White, 2005, p. 35), the concept of engagement fits within a heteroglossic understanding of discourse informed by Bakhtin (1981). From this social dialogic perspective, speakers and writers engage with previous written or spoken locutions or anticipate potential reactions from other authorial voices that have previously expressed or could choose to articulate contentious value positions on the issue under consideration. The notion of engagement therefore encompassesalthough it is not limited to- "all those locutions which provide the means for the authorial voice to position itself with respect to, and hence to 'engage' with, the other voices and alternative positions construed as being in play in the current communicative context" (Martin and White, 2005, p. 94). This framework of intersubjective positioning is adopted here in recognition of the heteroglossic nature of climate science blogs as sites of controversy where traditional understandings of evidence and expertise can be reinforced or undermined. Additional information on the way in which the notion of engagement is operationalized in this study is provided throughout section "Analysing CSBC bloggers' construction of intersubjectivity: Bias, dogma, peer review".

\section{Investigating bloggers' stances: Data and conceptual framework}

The Climate Science Blogger Corpus (CSBC) used in this study was compiled with a view to capture varied shades of opinion along the spectrum between the two polar extremes of the climate change debate. The selection of blogs included in CSBC was guided by three main criteria. As befits a corpus built to study how traditional understandings of expertise and evidence are contested in sites of techno-scientific dispute, the selected blogs adopt a clear and explicit stance on the climate change controversy. They also represent various blogging agendas, in terms of motivations and the individual or collective authorship of the chosen outlets. Importantly, CSBC includes only blogs whose authors granted their consent for the inclusion of their posts in the Genealogies of Knowledge Internet corpus, which placed additional constraints on the selection process. ${ }^{6}$

CSBC consists of 448,608 tokens extracted from five blogs dealing with climate change issues in the US, UK and Australia. Table 1 displays the composition of the corpus in terms of the blog's name, URL, number of posts and number of tokens for each blog. The bulk of the posts-typically between 500 and 1500 tokens each-were published between 2007 and 2019, although the vast majority were posted between 2014 and 2018. For the purposes of analysis and discussion, the five blogs included in CSBC are divided into two groups. The 'contrarian' subset (CSBC-CON) comprises three blogs-Australian Climate Madness, Science Defies Politics and Climate Depot. These seek to challenge, to varying degrees, the scientific consensus embodied

Table 1 Composition of the Genealogies of Knowledge Climate Science Blogger Corpus (CSBC).

\begin{tabular}{|c|c|c|c|}
\hline Blog & URL & \# posts & \# tokens \\
\hline \multicolumn{4}{|l|}{ CONTRARIAN SUBSET (CSBC-CON) } \\
\hline Australian Climate Madness & https://australianclimatemadness.com & 169 & 34,080 \\
\hline Science Defies Politics & https://defyccc.com/ & 49 & 48,414 \\
\hline Total CSBC-CON & & & 91,021 \\
\hline \multicolumn{4}{|l|}{ ACCEPTOR SUBSET (CSBC-ACC) } \\
\hline DeSmog UK & https://www.desmog.co.uk/ & 218 & 252,968 \\
\hline
\end{tabular}


in the IPCC reports and the national policies emanating from the panel's recommendations. The 'acceptor' subset (CSBC-ACC), on the other hand, consists of two blogs-DeSmog UK and Union of Concerned Scientists of the United States of America (UCSUSA)aligned with mainstream consensus. ${ }^{7}$ In light of the present study's goals, the relatively modest overall size of this data set visà-vis the collections that often underpin large-scale corpus-based studies does not constitute a major limitation. While capitalizing to some extent on the quantitative insights yielded by corpus analysis tools, this paper ultimately aims to offer a framework for analysing the linguistic expressions of intersubjective positioning deployed by bloggers in the climate change debate rather than identifying statistically salient linguistic patternings, as explained in section "Analysing CSBC bloggers' construction of intersubjectivity: Bias, dogma, peer review".

The contrarian subset (CSBC-CON). Australian Climate Madness, ${ }^{8}$ run by Simon Turnill, is an Australian blog carrying the subheading "Just don't tell me the debate is over". An engineer and lawyer by training, Turnill makes claims to contributory and interactional expertise and boasts the capacity to offer more reliable reportage on climate change matters than specialist journalists. As a self-proclaimed expert, he acknowledges that "climate change is happening-just like it has happened for 4.5 billion years, and will continue to happen" (Australian Climate Madness, n.d.); despite his lukewarm acceptance of the fundamentals of climate change, several sections of his blog feature links to sceptic material elsewhere. Significantly, Turnill calls for the need to "review the evidence for and against anthropogenic global warming dispassionately" (Australian Climate Madness, n.d.), thus tacitly hinting at the emotional dimension of the climate change debate. Of note is Turnill's concern about "the politicization of the scientific process" (Australian Climate Madness, n.d.) at the hands of both the Australian government and mainstream media which, in his view, is skewing the results of climate science. Turnill has been quoted as saying that he "really want[s] to see the integrity of the process upheld" (Bachelard, 2011), which signals the extent to which he favours process over output legitimacy. ${ }^{9}$

The interplay between climate change and politics is also one of the driving forces behind Science Defies Politics, ${ }^{10}$ a blog run by author, start-up founder, mathematician and cyber-security expert Leo Goldstein. This blogger's concern over the "pseudoscience of climate alarmism" in the US (Science Defies Politics, n.d.) arises from what he perceives as the country's rapid intellectual degeneration, which "has been especially pronounced in science, and [...] coincided with the erosion of the basic freedoms that have existed [in the US] for more than 200 years, like freedom of speech, religion, the press, and association" (Science Defies Politics, n.d.). Goldstein lays a claim to the possession of interactional and contributory expertise by claiming to have created his blog "with the goal of using scientific and technological knowledge, applying the scientific method, [and] being non-partisan and non-political-in this order" (Science Defies Politics, n.d.). Despite having acquired core expertise in other areas of science, he has reportedly funded denialist online ads proclaiming that global warming is a hoax, that climate science is not settled, and that there is no correlation between rising levels of greenhouse gases and higher temperatures all over the planet (Tabuchi, 2017).

Climate Depot, ${ }^{11}$ the third of the blogs included in the CSBCCON subcorpus, presents itself as a US-based "information clearinghouse and one stop shopping [sic] for reporters, policymakers, students, scientists and concerned citizens to get the latest information on global warming and other key environmental and energy issues" (Climate Depot, 2009). In practice, however, media reports on the work of Climate Depot conflate the project with its executive director. Having run the communication operations of Republican politicians in the past, Marc Morano is well-known for courting controversy through his frequent media appearances. The director of Climate Depot's stance vis-à-vis climate scientists and their expertise is articulated on the depot's website, as well as in the documentary Merchants of Doubt ${ }^{12}$ (Kenner, 2014), where Morano goes on record saying:

I'm not a scientist, but I do play one on TV occasionally. Ok, hell, more than occasionally. [...] You go up against scientists, most of them are going to be in their own little sort of policy wonk world or area of expertise. Very arcane, very hard to understand, hard to explain, and very boring (Merchants of Doubt Trailer, 2015).

The visibility of Climate Depot at the interface between science, politics and media is such that, despite being widely regarded as a source of unverifiable information seeking to undermine core experts and the scientific consensus on climate science, ${ }^{13}$ leading mainstream media ${ }^{14}$ acknowledge its outstanding capacity to fuel public climate change scepticism in the US.

The acceptor subset (CSBC-ACC). The Union of Concerned Scientists' blog ${ }^{15}$ - the first of the two outlets included in the CSBC-ACC subcorpus-bears witness to the increasingly frictional relations between US scientists, in their capacity as core experts, and the White House administration. As was also the case during G.W. Bush's presidency, Trump's officials have been known to 'sanitize' scientific reports on the environmental and economic effects of climate change after delaying their release for several months (Waldman, 2019). They have also been known to block the submission of written testimony on the implications of climate change for national security before the United States House Permanent Select Committee on Intelligence because "the scientific foundation of the analysis did not comport with the administration's position on climate change" (Schoonover, 2019). Understandably, these practices have been contested by the 250strong community of scientists, communication specialists and policy analysts whose remit is to "use rigorous, independent science to solve our planet's most pressing problems" (Union of Concerned Scientists, n.d.) or, as their blog subtitle states, to "use science to make change". The Union of Concerned Scientists' blog is therefore a good example of a virtual advocacy network driven by an activist agenda under which American core experts are now "organizing protests, educating the public, and shaming their local governments and national representatives into action" while stepping up their efforts to "communicate their science" amid the growing politicization of the climate change debate (Meyer, 2016). Their desire to assert their political agency in this debate is reflected in the content of their posts, which often launch specific attacks against specific politicians and governmental bodies.

Finally, DeSmog $U K^{16}$ was launched in 2014 , as part of the wider DeSmog Blog initiative, "to expose lobbying and spin around climate change and other environmental issues" (DeSmog UK, n.d.). Bound by the UK's National Union of Journalists code of conduct, the journalists and researchers blogging through the DeSmog UK platform seek to fight climate change misinformation by drawing on facts and hard evidence-ultimately working, as the blog subtitle proclaims, to "clear the PR pollution that clouds climate science". The premise underpinning DeSmog UK's blogging is that much of the climate denialism movement is funded by the fossil fuel industry as part of a wider attack on democracy. Delaying remedial action on climate change requires gaining influence over environmental and energy policy makers 
Table 2 Key lexical items for the study of intersubjective engagement in CSBC.

\begin{tabular}{|lll} 
Position in frequency list & Token & \# Occurrences \\
\hline 227 & consensus & 214 \\
1080 & bias & 55 \\
1250 & misinformation & 48 \\
1567 & conspiracy & 37 \\
1987 & controversy & 28 \\
2672 & peer-review & 19 \\
2941 & biases & 17 \\
3200 & dogma & 16 \\
\hline
\end{tabular}

as well as creating doubts in the minds of the public about the reliability of science-hence the need to stand up for scientific evidence as a means to protect our political institutions and public processes of deliberation from the interference of corporate lobbying (DeMelle, 2014). ${ }^{17}$

\section{Analysing CSBC bloggers' construction of intersubjectivity: Bias, dogma, peer review}

The study of engagement as a way of positioning one's authorial voice or dialogic perspective (Martin and White, 2005) has tended to focus on the analysis of grammatically marked stance and, less commonly, on paralinguistic devices and value-laden lexis (Biber, 2006). This paper contributes to redressing this imbalance by focusing on the bloggers' use of lexical items for the purposes of dialogic engagement. A list of the most frequent tokens in CSBC was generated to assist with the selection of the lexical items to be analysed. Having set a cut-off point of at least 15 occurrences, the list was scrutinized to identify relevant evaluative tokens. To ensure that the analysis of my two relatively small subcorpora retained a strong focus on the most productive lexical expressions of engagement, I concentrated on selected nouns and items that function as pre-modifiers within noun phrases. Based on the frequency list, pre-modifying items within noun phrases were used in CSBC much more frequently than other word classes to negotiate intersubjectivity. Tokens belonging to more than one syntactic category (e.g. 'objective', which can potentially act as a noun or an adjective) were also discarded to ensure that the lexical items under analysis were semantically and syntactically comparable. Finally, the list was filtered to retain only those items used to qualify perceptions and applications of climate science, leaving out labels that can be used to refer both to individuals and policies (e.g. 'warmist', 'sceptic'). Among the items featuring in the final list to be considered for analysis (Table 2), and in consideration of space limitations, this paper explores only instances of engagement realized through lexical items pertaining to the exercise of scientific expertise, i.e. bias/biases, dogma and peer review. Consequently, it leaves out tokens like misinformation or conspiracy that, while evaluative, do not refer primarily to standards of epistemological value. The centrality of peer review systems in the production of expert knowledge by weeding out scientific biases and dogmatic premises accounts for its selection alongside the other two items.

My analysis of bloggers' alignment with their putative readership and the issues construed as matters of contention in their blog posts will examine the construction of engagement primarily through 'dialogically contractive' structures (Martin and White, 2005). ${ }^{18}$ Dialogically contractive approaches to the negotiation of intersubjectivity "challenge, fend off or restrict the scope" of alternative positions and voices within heteroglossic contexts (Martin and White, 2005, p. 102). While they do not acknowledge explicitly what others may think about the proposition at hand,

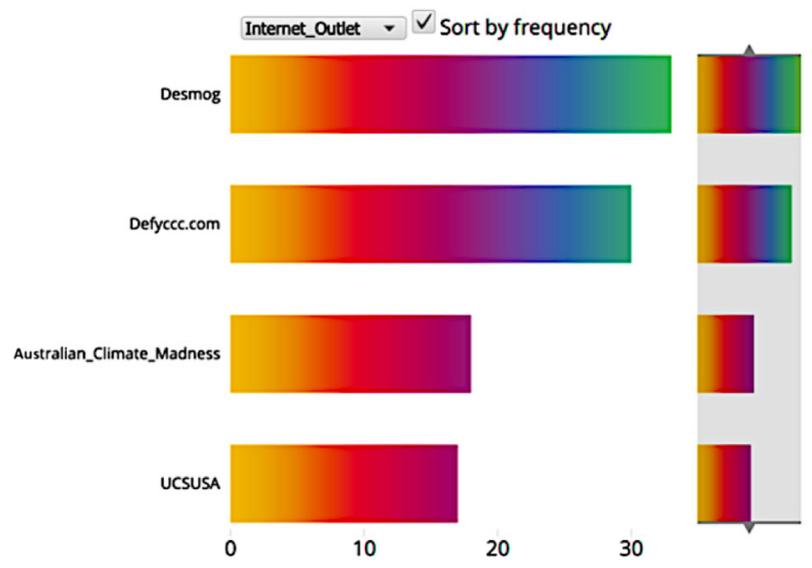

Fig. 1 Metafacet visualization for a concordance featuring bias/-es/-ed in CSBC (102 lines), filtered by Internet outlet and sorted by frequency.

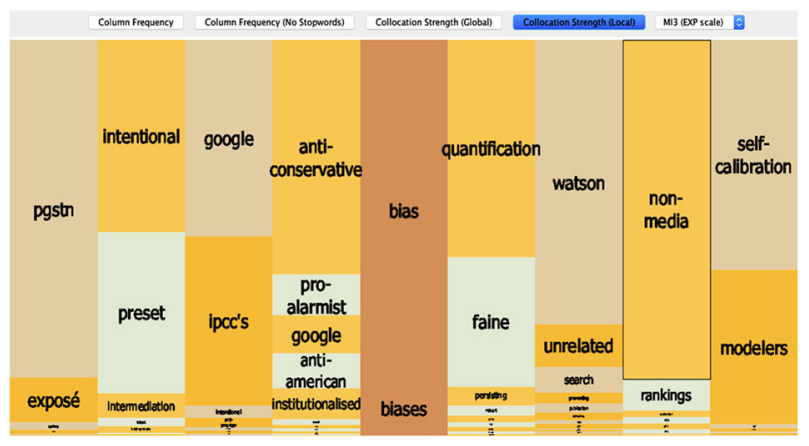

Fig. 2 Mosaic visualization of bias/-es in CSBC-CON (34 lines). Collocation strength: Local, MI3 (EXP Scale). ${ }^{22}$

contraction-oriented resources make an important contribution towards the construction of dialogic positioning. By framing textual propositions as being up for discussion, dialogically contractive lexis construes a readership that is receptive to further argumentation and discussion, whether it agrees or disagrees with the blogger's stance. Bias/-es, peer-review and dogma are examples of dialogically contractive lexical items featuring in CSBC that will now be analysed in turn. Specifically, they fall under the subcategory of "pronouncing" resources, for they allow bloggers to foreground their own subjectivity, while implying "the presence of some resistance, some contrary pressure of doubt or challenge against which the authorial voice asserts itself" (Martin and White, 2005, p. 128).

A Metafacet visualization ${ }^{19}$ (Fig. 1) for a concordance listing 102 occurrences of bias, biases and biased in CSBC reveals that these tokens are used in four of the five blogs included in the corpus. Considering that the size of CSBC-ACC is approximately four times that of CSBC-CON, the fact that the occurrence of these tokens, measured in absolute terms, is similar across the two subcorpora shows that their frequency is significantly higher in the contrarian subset in proportional terms.

A search for bias* in the CSBC-CON corpus returns 34 occurrences of bias or biases-once the lines where these tokens are used as a verb have been removed from the concordance using a 'Delete Line' function available through the GoK interface. ${ }^{20}$ As the number of occurrences retrieved is relatively low, the collocational patterns captured by the Mosaic visualization ${ }^{21}$ (Fig. 2) for this search are not scrutinized primarily with a view to discriminate between patterns on the basis of their statistical saliency. Instead, this visualization is used to examine the associations that the search item establishes with other lexical choices 


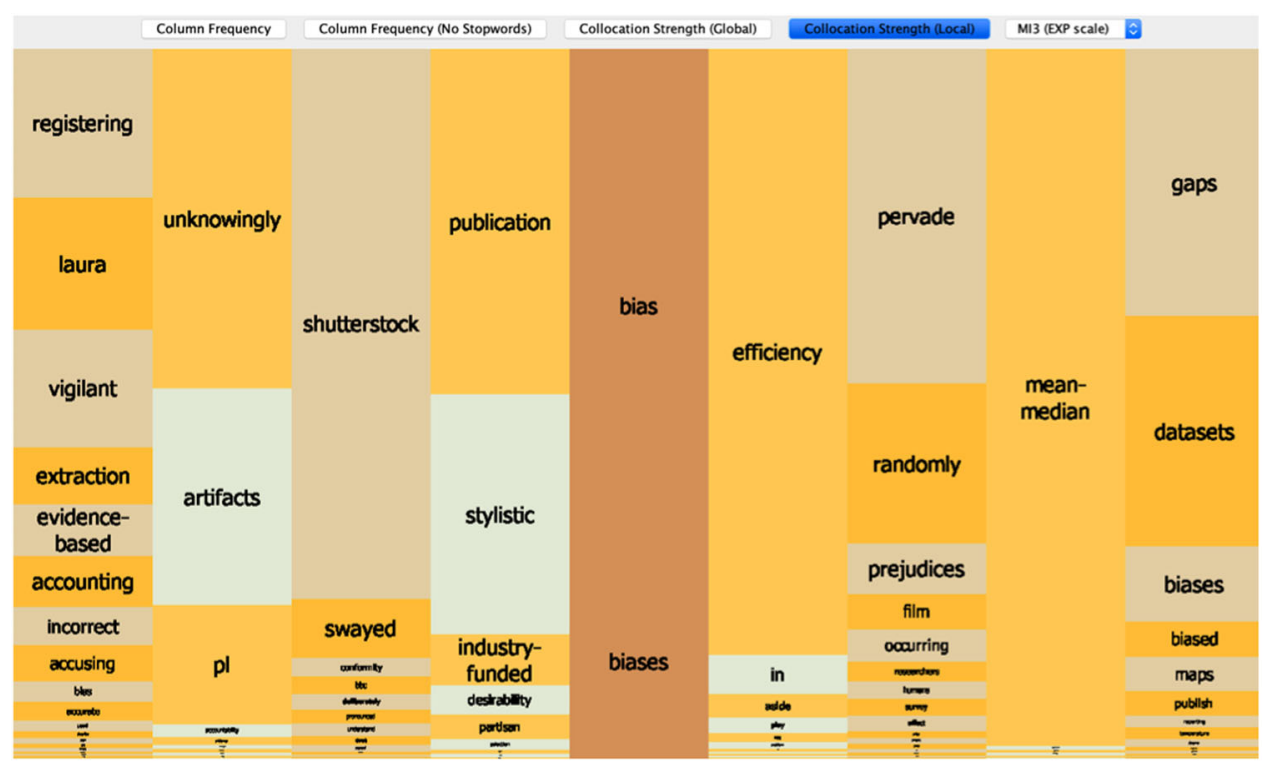

Fig. 3 Mosaic visualization of bias/-es in CSBC-ACC (38 lines). Collocation strength: Local, MI3 (EXP Scale).

in its environment-as displayed in the Mosaic tiles on both sides of the search item. Ultimately, the network of lexical choices observed around the search item is analysed to establish whether or not the authorial voices in CSBC-CON and CSBC-ACC seek and manage to construct coherent authorial subjectivities through which bloggers can position themselves in the debate vis-à-vis their dialogic adversaries.

As the mosaic in Fig. 2 shows, contrarian outlets label biases relating to climate change science as 'pro-alarmist' in L1 position (i.e. in the first column to the left of the search node) or attribute them to the 'warmist' stance associated with scientific consensus, also in L1 position. Further contrarian outlets present such biases as 'intentional' in L3 position (i.e. in the first column to the left of the search node) and hence partisan. Crucially, CSBC-CON outlets are keen to expose the 'institutionalized' (position L1) nature of biases in major institutions and corporations, some of which-like IPCC (example 1) and Google (multiple concordance lines) - are captured in the Mosaic display in Fig. 2 (positions L2 and $\mathrm{L} 1 / \mathrm{L} 2$, respectively. Other corporations such as Wikipedia (example 2) and ABC (example 3) do not appear in the Mosaic display but fit the same pattern. The contrarian authorial voice also seeks to assert itself against what it perceives as the ideological and political nature of climate change biases, which are framed as 'anti-conservative' (L1), 'heavy leftist' (L1) and hence 'anti-American' (L1) (example 2).

(1) Text int $001459 \mid \mathrm{He}$ is healthily sceptical of the AGW scaremongers (and has written books on the subject) and this week takes apart the crumbling edifice that is the IPCC [...] John McLean has written a superb exposé of the inherent bias of the IPCC: Climate Science Corrupted [...] it is an eye-opening read. ${ }^{23}$

Source: Turnill (2010a), published in Australian Climate Madness.

(2) Text int001292/Wikipedia has well known problems that include: the unexplained exit of respected executives and directors; the foreign control of the Board of Wikimedia Foundation and its corporate body; the leftist background of the CEO and key members of the executive team; heavy leftist and anti-American bias; tight control by the Board of the nomination, election, and certification of the editorial hierarchy; and susceptibility of the nomination and election process to fraud by the executives and/or the Board members.

Source: Goldstein (2017b), published in Science Defies Politics.

(3) Text int001410 $\mid \ldots$ the ABC (Australian Broadcasting Corporation) is a mouthpiece for Labor, the Left in general and the Green agenda. OK, you're saying, tell me something I didn't know. Yes, yes, true, but these two examples perfectly encapsulate the blatant and institutionalized bias of the ABC, which flies in the face of its legal obligations as an impartial public broadcaster, but somehow it escapes any sanction for doing so.

Source: Turnill (2012), published in Australian Climate Madness.

Searching for bias* in the CSBC-ACC corpus returns 38 concordance lines where bias or biases are used as nouns. The scrutiny of collocates featured in the Mosaic visualization of this subcorpus (Fig. 3) indicates that a significant number of the occurrences of bias and biases in CSBC-ACC can be observed in discussions on scientific methodology (e.g. 'datasets', position R4 in the Fig. 3 Mosaic) in example 4; research equipment (e.g. various types of instruments that do not appear in the Mosaic display but fit the same pattern) in example 5; research metricse.g. 'bias efficiency' (position R1) versus 'mean-media approaches' (position R3) and the science 'publication' system (position L1). Of particular note is the role that 'industry-funded' (position L1) research plays in the production of biased climate science knowledge, as is further illustrated in example 6.

(4) Text int002567 $/$ Moreover, each instance of the presumed onset was not randomly chosen but chosen specifically because of the low subsequent warming. We describe this as selection bias ... some of the biases that affect the datasets and projections were known, or knowable, at the time. Source: Kirby (2018), published in DeSmog UK.

(5) Text int001332 In fact, NOAA scientists were using the scientific method to identify the bias that exists in temperature measuring instruments and making their data more accurate by taking this bias into account. We all apply this same process when we compare the results of different bathroom scales, time pieces, meat thermometers, or fuel gauges in cars. 
Source: Gunther (2018), published in Union of Concerned Scientists.

(6) Text int001354|.. American Coal Council, the U.S. Chamber of Commerce, Monsanto, the American Enterprise Institute, and, of course, the Alliance. The report follows a familiar pattern, generally calling into question the science behind the health impacts of [insert pollutant here], frequently based on a convoluted and biased modeling effort masquerading as science. If you're familiar with the Disinformation Playbook, then what's in the Alliance's paid-for report will sound familiar ...

Source: Cooke (2018), published in Union of Concerned Scientists.

In the preceding examples, CSBC-ACC bloggers make use of 'pronouncing' lexical items like bias to acknowledge the heteroglossic diversity of approaches to the study of climate science, and construct a coherent authorial voice to challenge the biased nature of the dialogic alternative at play, i.e. contrarian science. Such accusations of bias, however, are articulated differently in each subcorpus. Contrarian bloggers place particular emphasis on the ideological dimension of the biases underpinning the mainstream scientific consensus endorsed by institutions and corporations-mobilizing nonepistemic values in an indirect role (Douglas, 2009). By contrast, CSBC-ACC voices seek to legitimize their own stance by foregrounding the unsavoury sources of contrarian scientific funding, and the weaknesses of the methods and protocols used by climate change deniers. But with core experts having to play an increasingly activist role in defense of their work, CSBC-ACC bloggers occasionally draw attention to the ideological and/or political dimension of contrarian biases. In example 7 , for example, biases are reframed as desirable strategies to redefine social values and accelerate the pace of progress in public life.

(7) Text int000181/Are our water resources managed by what's measurably in the reservoir, or whether we feel that glass is half full or half empty? Did the US Department of Defense develop a climate change strategy based on whimsy, or on data and analysis? Yes, bias can be introduced when values come in to play, and this can be a good thing (e.g., when society decides to recognize the intrinsic value of species or landscapes, or intangibles like well-being) or a bad thing (e.g., when we only value what certain messengers have to say and devalue all others).

Source: Spanger-Siegfried (2016), published in Union of Concerned Scientists.

My analysis has so far shown how each group's authorial subjectivity is underpinned by a distinctive line of attack against alternative positions. CSBC-CON voices conceptualize climate science biases as value-driven flaws; for CSBC-ACC bloggers, on the other hand, biases result from the use of unsuitable instruments, poorly designed protocols or modelling exercises-as illustrated in examples 4-6. In the remainder of this section, I aim to test whether the corpus-assisted methodology adopted in this study can yield further insights into the differences between the strategies that contrarian and acceptor bloggers deploy to construct intersubjectivity, focusing on two additional pronouncing lexical resources, dogma and peer-review-both of which are directed at tacitly or explicitly identified counter positions.

A search for dogma* in CSBC returns a 16-line concordance. The Metafacet visualization in Fig. 4 brings into sharp relief the uneven distribution of dogma across subcorpora. 12 occurrences of the term are found in two CSBC-CON blogs (Science Defies Politics and Australian Climate Madness), even though their combined size in terms of numbers of tokens is approximately a

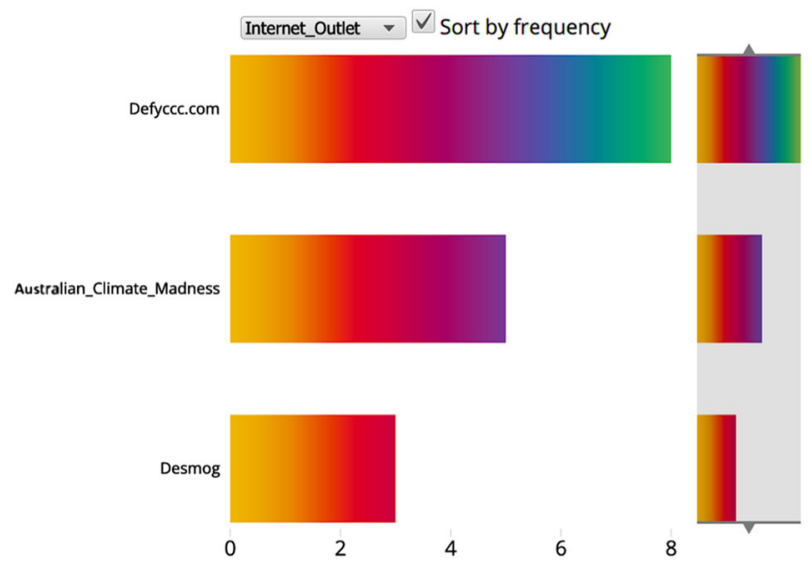

Fig. 4 Metafacet visualization for a concordance featuring dogma in CSBC (16 lines), filtered by Internet outlet and sorted by frequency.

third of the size of DeSmog UK, the only CSBC-ACC blog where dogma is used.

The full concordance of dogma in the CBSC-CON corpus (Fig. 5) provides further evidence that contrarian bloggers seek to discredit climate science by framing this form of knowledge as value-laden, rather than evidence-driven. Climate science is conflated with 'dogma' (line 1) or, more elaborately, with 'climate (change) (cult) dogma' (lines 2-5). The fact that these lexical items are often preceded by the article 'the' (lines 2-4, 9-11), the possessive adjective 'its' (lines 5-7), or the demonstrative determiner 'this' (line 12) emphasizes that a single, unquestioning belief has taken over the systematically organized body of knowledge and practices that scientists would be normally expected to subject to critical scrutiny and revision. It can be further observed that contrarian bloggers occasionally use 'science' and 'dogma' in each other's co-textual vicinity as a strategy directed against their dialogic adversaries. Specifically, contrarians frame the use of 'science' - complete with the strong connotations of respectability that the term typically evokes-by mainstream climate change experts as a cloak to conceal the flaws of their 'dogma' (e.g. line 5: 'calls its dogma science'; line 6: 'calling it "settled science"). As understood by the contrarians' authorial voice, the climate change dogma is politicized and does not lend itself to scrutiny; on the contrary, it demands being accepted as undisputed truth and stands in opposition to sound research where values are used in a direct role (e.g. line 6: 'refuses to debate its dogma'; line 7: 'declared its dogma to be the undisputed truth'; and 12: 'prohibiting scientific research that contradicts this dogma'). As a result, those subscribing to the climate change dogma are 'blinded' (line 1) and 'brainwashed' by it (line 9).

The argument that warmist biases are firmly embedded in policy-making processes and corporate strategies-as articulated in CSBC-CON discourses-is consistent with the dialogic construction of climate change dogma by contrarian bloggers. CSBC$\mathrm{CON}$ voices, for example, attribute the responsibility for the development and reinforcement of the climate change dogma to ministers (e.g. line 1, 'she'-which refers back to Australian Senator Penny Wong); multilateral institutions and organizations (e.g. line 2: 'lawless UN agencies'; and line 3: 'the IPCC or UNFCC'); corporations (e.g. line 4: 'Google'); and climate alarmists (e.g. line 6: 'alarmist movement'; line 7: 'climate alarmism' and line 9: 'global warming alarmism'). Interestingly, the contrarian trope that business giants are aligned with left-wing stances on climate change, as discussed in my earlier analysis of CSBC-CON discourses on scientific biases, is also used here to decry the pervasiveness of the climate dogma (see line 4 , expanded in example 8). In trying to contest their dialogic 


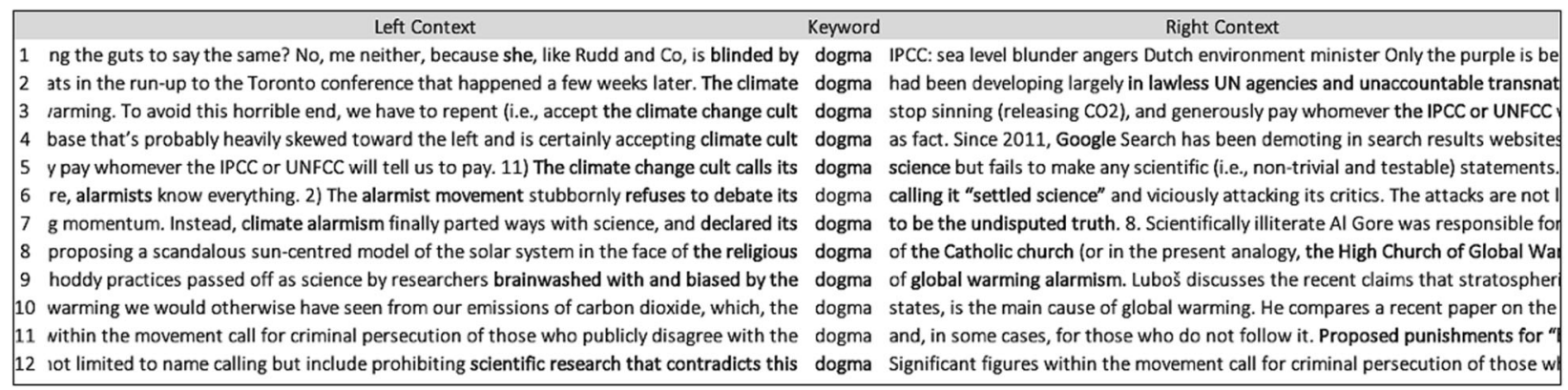

Fig. 5 Concordance lines (dogma) extracted from CSBC-CON and ordered alphabetically by the word in position 1 to the left.

alternative, CSBC-CON voices take the characterization of climate science as a value-driven form of knowledge one step further, framing it along religious lines-whether by presenting global emissions as a 'sin' requiring 'repentance' (line 3, expanded in example 9), or comparing the contrarians' challenge to climate science with Galileo's actions in defiance of the 'Catholic Church' (line 8, expanded in example 10).

(8) Text int $001050 \mid \ldots$ the Main Part of the San Francisco AI Google Search has an internal state which includes a huge knowledge base that's probably heavily skewed toward the left and is certainly accepting climate cult dogma as fact. Since 2011, Google Search has been demoting in search results websites that disagreed with its "facts."

Source: Goldstein (2017a), published in Science Defies Politics.

(9) Text int001034|The climate change cult has its own eschatology-calamities, catastrophes, and the end of the world caused by global warming. To avoid this horrible end, we have to repent (i.e., accept the climate change cult dogma), stop sinning (releasing $\mathrm{CO} 2$ ), and generously pay whomever the IPCC or UNFCC will tell us to pay.

Source: Goldstein (2015), published in Science Defies Politics.

(10) Text int001575 /If Rudd had any idea of the history of science (or in fact about anything at all), he would have realized that it was Galileo who was in the position of today's climate sceptics, bravely proposing a scandalous sun-centred model of the solar system in the face of the religious dogma of the Catholic church (or in the present analogy, the High Church of Global Warming), which stood firmly by the biblical, faith-based, earth-centred model. And for this (ultimately correct) interpretation of the workings of the solar system, Galileo was sentenced by the Pope to house arrest...

Source: Turnill (2009), published in Australian Climate Madness.

The three concordance lines featuring occurrences of dogma in CSBC-ACC come from blogs posted in DeSmog UK. The fact that dogma is presented in these three instances (examples 11-13) as part of quoted statements enclosed in double quotation marks signals that this lexical resource is being used to construct a 'dialogically expansive' position (Martin and White, 2005)-in contrast to contrarian bloggers' efforts to head off alternative views through contractive strategies. The use of dogma by DeSmog UK voices represented in CSBC-ACC through dialogically expansive structures can therefore be said to "actively make allowances for dialogically alternative positions and voices" (Martin and White, 2005, p. 102), decoupling "the proposition from the text's internal authorial voice by attributing it to some external source" (Martin and White, 2005, p. 111). By using this expansive strategy, CSBC-ACC bloggers engage directly with individual contrarian voices, foregrounding the extent to which the latter's involvement in this heteroglossic setting is driven by ideology and prejudice. Climate change acceptors thus manage to ground the viewpoints of contrarian authoritarian voices (represented by a former Australian Prime Minister in example 11; a British political strategist and lobbyist associated with the Vote Leave campaign in example 12; and a Brazilian diplomat appointed by President Jair Bolsonaro in example 13) in overt manifestations of subjectivity-ultimately exposing the extent to which the resources deployed to construct CSBC-CON's dialogic stance are at odds with discursive conventions in scientific debate.

(11) Text int 002583 | In 2013, Howard said climate "zealots" had turned the issue into a "substitute religion". Abbott, who trained to be a Roman Catholic priest, called climate change a "post-Christian theology" and said the decline of religion in society had left a hole in which other forms of "dogma" could take root. Measures to deal with climate change, which Abbott said would damage the economy, likened to "primitive people once killing goats to appease the volcano gods". "At least so far," he said, "it's climate change policy that's doing harm. Climate change itself is probably doing good; or at least, more good than ...

Source: Mathiesen (2017), published in DeSmog UK.

(12) Text int $002562 \mid \ldots$ contemporary cultural debates in the UK and was founded by Ukip Assembly Member Peter Whittle. The New Culture Forum argues that the right has won the economic argument but that the liberal left still dominates the cultural space, with its website saying the group was created to "challenge the dogma and relativism of the establishment and redefine the parameters of the cultural and political debate".

Source: Farand and Hope (2018), published in DeSmog UK.

(13) Text int002594 $\mid \ldots$ the point of paroxysm over the last 20 years with the ideology of climate change, the climatism," he wrote in the blog post. This movement gathered data "suggesting a correlation" between rising temperatures and $\mathrm{CO} 2$, he claimed. They "ignored data suggesting the opposite... and created a 'scientific' dogma that no one else can contest or he will be excommunicated from good society-exactly the opposite of the scientific spirit." His claims contradict not only the vast majority of climate scientists but also the consensus among world leaders.

Source: Mathiesen (2018), published in DeSmog UK.

Moving on to peer review, the analysis examines how the contrarian and acceptor dialogic positions align themselves with the very system designed to recognize and confer expertise on individual scientists and organizations. Technically, references to peer review systems should not serve to advance pronouncing strategies, whether contractive or expansive. While the term invokes a backdrop of heteroglossic diversity where certain views prevail over others, peer reviews are envisaged to help holders of different views to negotiate an agreed intersubjective stance based 


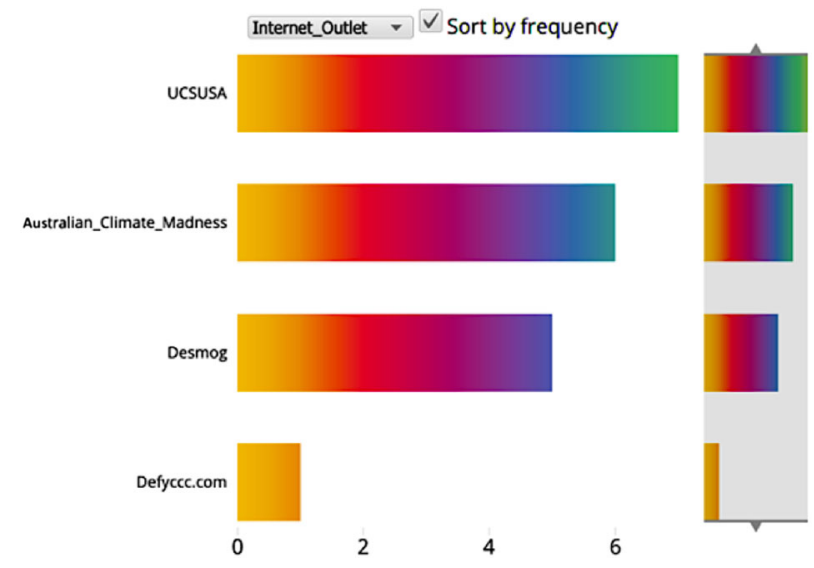

Fig. 6 Metafacet visualization for a concordance featuring peer review in CSBC (19 lines), filtered by Internet outlet and sorted by frequency.

on widely accepted epistemic traditions. In other words, the integrity of the peer review system should in principle remain outside the bounds of dialogic confrontation, insofar as it should mobilize epistemic values in a direct role. Consequently, examining how authors in each subcorpus choose to characterize the impact of peer review evaluations on policy-making and social perceptions of climate change should reveal whether bloggers engage with the peer review culture (process) in the same way as they do with the science that peer reviewers choose to endorse or contest (output).

A Metafacet visualization (Fig. 6) for a concordance listing 19 occurrences of peer review in CSBC shows that this lexical item is present in both subcorpora and that its frequency is proportionally higher in the contrarian blogs, given that the size of the CSBC-CON subcorpus is only a fourth of its CSBC-ACC counterpart. A Mosaic visualization based on a 7-line concordance of peer review in the CSBC-CON blogs (Fig. 7) indicates that references to the peer review system are strongly associated with 'alarmism' (position L1 in Fig. 7 mosaic) in general, and 'IPCC' (position R4) in particular. The biased nature of peer reviews, as perceived by contrarian bloggers, explains the occurrence of lexical items like 'corruption' (position L3) or 'skewing' (position L2) in the vicinity of the search term, and the labelling of these instruments of evaluation as 'schmeer-reviews' (position $\mathrm{R} 1$, expanded in example 14). Contrarians' scepticism towards peer reviewing also accounts, for example, for the differentiation made between 'proper' (position L1) peer reviews and 'pal reviews' (not captured in the mosaic display in Fig. 7) - the latter being an important tool to quash scientific dissent (example 15).

(14) Text int001469|IPCC quotes WWF (again) ... gets it wrong (again) Peer-review, schmeer-review. Half of the IPCC's last report was based on stuff like this, papers from deep green advocacy groups like WWF which happened to fit nicely with the IPCC's pre-conceived agenda of climate alarmism. And they've been caught with their pants down yet again, this time on the ...

Source: Turnill (2010b), published in Australian Climate Madness.

(15) Text int $001400 \mid \ldots$ that one of the key scientific reports on which that conclusion was based was not subjected to those proper, rigorous processes and that "corners were cut" in order to rush it through. But that's OK isn't it, because the consensus boys don't have to bother with tedious inconveniences like proper peer-review. Just ask the IPCC. Anyway, they can rely on "pal-review" if they get stuck. And the hypocrisy of the EPA is breathtaking, casually brushing aside the criticisms as a trivial irrelevance. Can you imagine the outrage if this had been a sceptical report? Double standards exemplified. Source: Turnill (2011), published in Australian Climate Madness.

A Mosaic visualization based on the output of the 12-line concordance for peer review in the CSBC-ACC corpus (Fig. 8), on the other hand, features peer review at the centre of a very different network of lexical relations. A detailed scrutiny of the concordance confirms that acceptor bloggers associate peer review with the established process of academic publishing, under which scientists submit and publish their work in journals that uphold rigorous standards and editorial policies based on epistemic values - unlike the case reported on in example 16, involving a journal run by a 'climate science denier editor'. The occurrence of items evoking more negative connotations-e.g. 'sloppy' (position R3 in Fig. 8 mosic) and 'corruption' (position R4) - in the vicinity of peer review is, again, attributable to the use by CSBC-ACC bloggers of an expansive engagement strategy to convey the speech of a directly referenced dialogic adversary (example 17: 'Melanie Phillips ... argues that ... the peer-review process gets sloppy...').

(16) Text int001997/The publisher of an academic journal beloved by climate science deniers has been revamped to ensure it meets industry standards of peer-review and editorial practice. Its climate science denier editor has also stepped down. Long a home for papers that cast doubt on climate science and the seriousness of climate change, Energy and Environment was recently bought by publishing behemoth SAGE. As part of the acquisition process, ... Source: Hope (2018), published in DeSmog UK.

(17) Text int002589| Science is Turning Back to the Dark Ages In this comment piece by Melanie Phillips, a right-wing British journalist and commentator, she argues that science has lost much of its academic integrity and rigour as scientists cut corners: the peer-review process gets sloppy, corruption pervades institutions, and conformity drives biases. However, this piece itself somewhat fails in its 'scientific integrity' and 'rigour' as it echoes the above Times article on the "exaggeration" of ocean acidification.

Source: Mandel (2016), published in DeSmog UK.

On the whole, the contrarian stance on peer reviewing is consistent with its pronouncements on biases and dogmas. Challenges are mounted against the interference of the scientific and political establishment with climate science, and the instrumentalization of peer reviews to legitimize a partisan "conduct of the climate science system" (van Rensburg, 2015, p. 141)-rather than against the material practices that embody the work of producing climate science knowledge before it is submitted for peer scrutiny. Consistency can also be observed in the way acceptor bloggers construct their dialogic position on peer reviewing, drawing attention to the practices that underpin the production of knowledge in legitimized knowledge networks and exposing the subjective pronouncements that voices on the contrarian side of the debate mobilize to construct their intersubjective stance.

\section{Conclusion}

The use of selected 'pronouncing' lexis like bias, dogma and peer review by contrarian actors to negotiate their intersubjective positioning within the blogosphere reveals a mismatch between some of their avowed intentions and their actual authorial voices as bloggers. As discussed in section "Investigating bloggers' stances: Data and conceptual framework", CSBC-CON bloggers present themselves as endowed with the cultural competence 


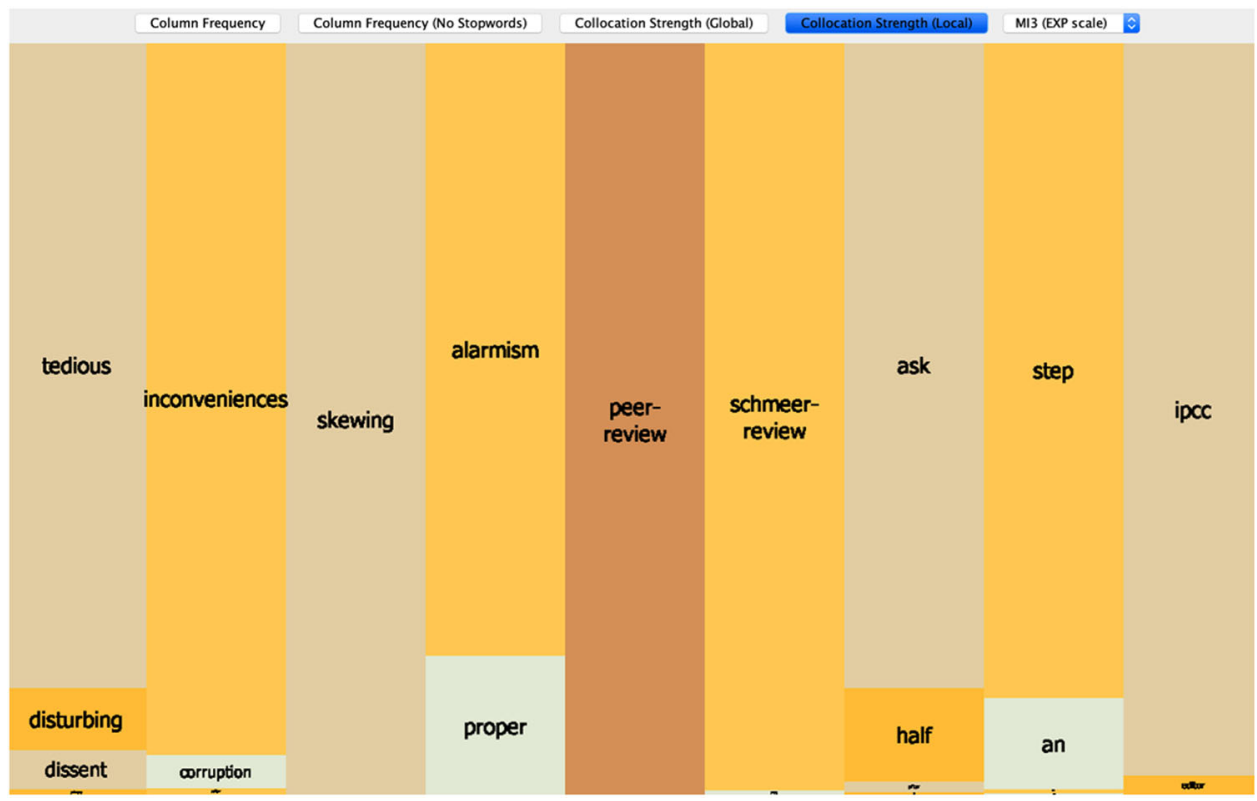

Fig. 7 Mosaic visualization of peer review in CSBC-CON (7 lines). Collocation strength: Local, MI3 (EXP Scale).

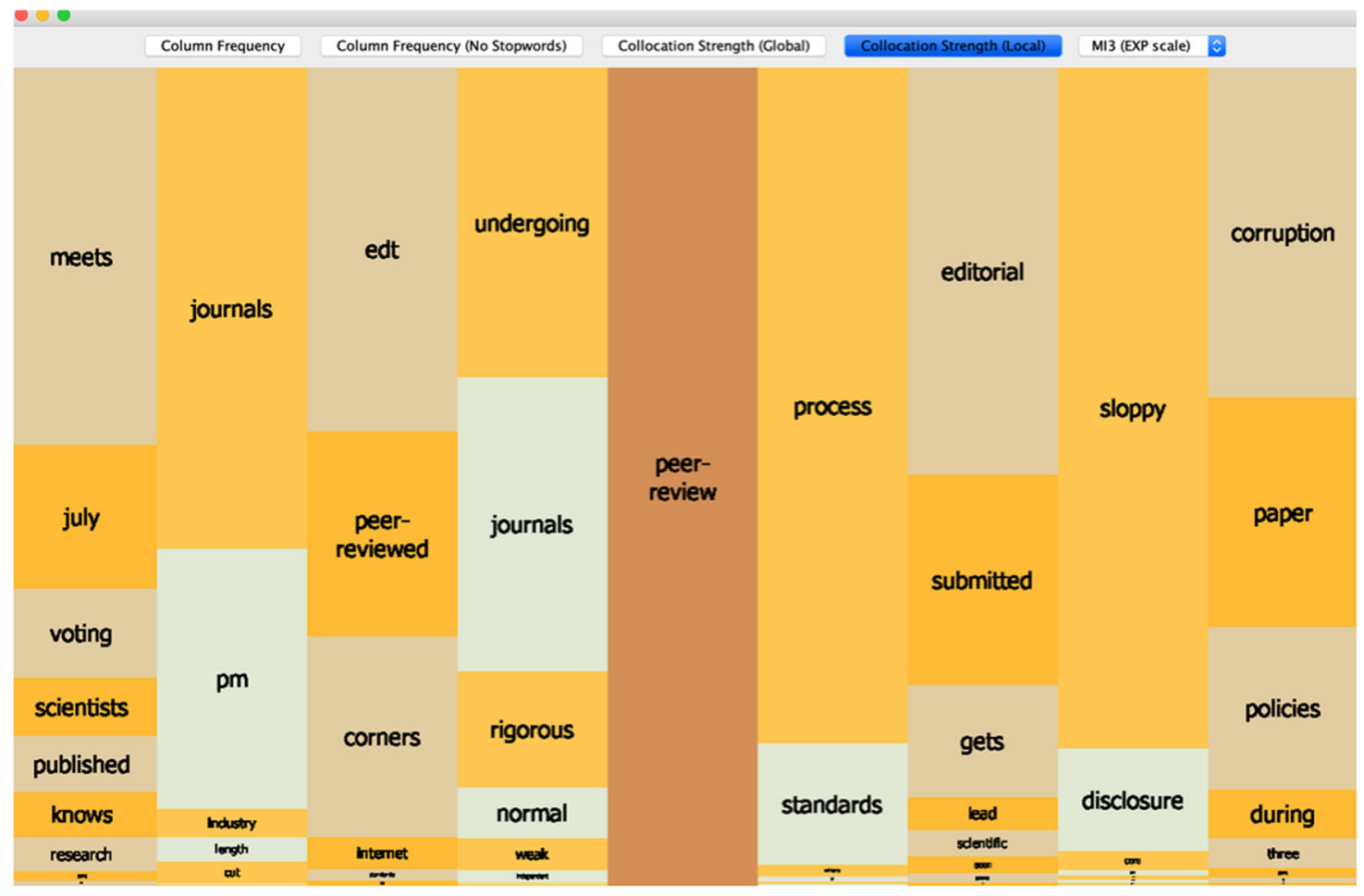

Fig. 8 Mosaic visualization of peer review in CSBC-ACC (12 lines). Collocation strength: Local, MI3 (EXP Scale).

required to master interactional and contributory expertise in the field of climate science; accordingly, they claim to be driven by the need to assess evidence for and against climate change dispassionately, as a way to uphold the integrity of the climate science, and purport to provide a non-partisan and non-political critique of relevant developments. However, the analysis of this subcorpus shows that, in positioning themselves with respect to the acceptors' stance, contrarian bloggers resort to characterizing mainstream scientific consensus precisely in terms of the latter's alignment with institutional policies, corporate interests or left- wing agendas at odds with national interests. As shown by the analysis, the inherent biases of the 'consensus science', that contrarian bloggers frame as value-driven flaws, are elevated to the category of church dogma in CSBC-CON discourses. By purportedly exposing the centrality of non-epistemic values in consensus climate science, CSBC-CON bloggers' stance becomes imbued with political overtones, which facilitates the derivation and communication of their sceptic perspective. On the surface, contrarian bloggers' pledge to uphold process legitimacy would appear to be somewhat more congruous with their stance on the 
peer review system. As shown in section "Analysing CSBC bloggers' construction of intersubjectivity: Bias, dogma, peer review", the CSBC-CON authorial voice questions the reliability of peer reviews insofar as these are conducted exclusively by core experts (without the involvement of their contributory or interactional counterparts) influenced by pervasive institutional and corporate vested interests. Ultimately, however, contrarian bloggers do not single out any specific procedural flaw of the evaluation process, opting instead to decry the unacceptable politicization of consensus science-where values, they argue, shape the research process from its very early stages.

By contrast, the biases identified by CSBC-ACC bloggers refer primarily to the consequences of ill-informed conceptual or methodological decisions, and of skewed calibration and measurements while gathering evidence. In other words, the analysis shows that acceptor bloggers are normally bound by values used in a direct role (Douglas, 2009), i.e. they are more likely to mobilize epistemic values circumscribed by the methodological norms of the certified scientific community. This understanding of scientific biases as relatively unintentional consequences of non-partisan exercises of agency is consistent with the complete absence of references to climate science dogma in the Union of Concerned Scientists blog. Significantly, it also brings into sharp relief the fact that occurrences of this lexical item in Desmog UK are confined to statements by public figures in the sceptic camp, that are quoted verbatim to expose their prejudiced nature. The coherence of the CSBC-ACC's authorial voice is reinforced through their characterization of peer reviews as gate-keeping instruments underpinned by established epistemic frameworkswhere values are deployed in a direct role-and forms of expertise. The analysis shows how, on occasions, core experts adopt a more adversarial stance in their blog posts that mobilizes nonepistemic values to discredit contrarian voices.

Although their readership in absolute terms is often small, climate change blogs attract a relatively high number of influential readers, including journalists, who facilitate the penetration of bloggers' views and their policy disputes into mainstream reporting and public discourse (Farrell and Drezner, 2008). This study has advocated the need to compile and interrogate corpora consisting of climate blogs, an increasingly influential genre complementing previous research on scientific controversy as reported in traditional media. The findings outlined here reveal the value-laden character of contrarian views, and show how acceptor bloggers attempt to construct an authorial voice driven by 'the science', while drawing on dialogically expansive strategies to foreground their opponents' prejudiced voices for strategic reasons. This relatively small corpus therefore confirms that, in addition to prompting reflection on the use of knowledge in various forms of public decision-making, both contrarian and acceptor bloggers seek to manage public perceptions of climate change using different approaches. More work is needed to establish how other types of evaluative lexis influence the bloggers' engagement with alternative stances, and whether these are consistent with the discourses that this paper has reported on. Exploring the similarities and differences between the authorial voices constructed in blog posts and in the wider range of online genres included in the Genealogies of Knowledge Internet corpus would yield further insight into the negotiation of intersubjectivity and expertise in an increasingly multivoiced debate.

Received: 29 November 2019; Accepted: 19 August 2020; Published online: 15 September 2020

\section{Notes}

1 An itemized list of the articles included in the Genealogies of Knowledge Internet corpus is available at http://genealogiesofknowledge.net/corpora/internet-corpus/.

2 Unlike 'sceptic' and 'catastrophist' discourses, 'gradualism' postulates that climate change is happening gradually and that economic activities can be adjusted to minimize the impact of human impact on the environment (Dayrell and Urry, 2015).

3 Full details on the composition of CSBC are provided in section "Investigating bloggers' stances: Data and conceptual framework".

4 Recent studies show that climate change scientists are also taking to Twitter to interact with fellow scientists, journalists, civil society and politicians-and adjusting their communication style to their target audience (Walter et al., 2019).

5 SEE's normative theory of expertise has been strongly criticized by advocates of the social constructivist approach, who have characterized it as a reversion towards technocracy (Wynne, 2003). Although Collins and Evans intended their theory to be "compatible with SSK" (2002, p. 239), critics argue that it opens up opportunities for scientists to flout democratic norms of transparency and escape oversight from civil society, thereby putting the epistemics of public deliberation in jeopardy (Jasanoff, 2003, p. 158). Acting as "inadvertent agents of the reproduction of an established set of institution reflexes" (Wynne, 2006, p. 217), scientists may remove the political from the policy-making equation (Wynne, 2016, p. 101), in what would amount to an act of "scientific denial [or] dishonesty" (Wynne, 2016, p. 106). Other critics have drawn attention to various aspects of the dialectic between scientists and experiencebased experts, noting that SEE does not set out to explain how the right of noncredentialed specialists to participate in technical decision-making accrues or is recognized by trained experts (Rip, 2003). In their view, under SEE's normative theory of expertise, scientists' dogmatism challenges and undermines the socially sensitive and adaptable reasoning displayed by lay publics, effectively turning policymaking on contentious issues into an activity where "technical and social criteria confront each other without a common metric" (Fischer, 2009, p. 45).

6 Although the research carried out by the Genealogies of Knowledge project is compliant with the spirit of the 2014 UK copyright exception for text and data mining for non-commercial research (Borghi, n.d.), the project team has actively sought to secure informed written permission from bloggers before including their material in the corpus. As is also the case with the publishers and authors of other online material held in the Genealogies of Knowledge Internet corpus, bloggers who agreed to have posts sourced from their websites are listed in the Credits page of the project's website-available at https://genealogiesofknowledge.net/credits/.

7 Although their aims and methodology are very different from those driving the present study, the dichotomy between 'contrarians' and 'acceptors' proposed by Diakopoulos et al. (2014) is adopted here to bundle the various sensitivities without necessarily presenting them as outsiders/insiders, or in terms of their majoritarian/ minoritarian status.

8 The itemized list of the Australian Climate Madness posts included in CSBC-CON is available at https://genealogiesofknowledge.net/credits/australian-climate-madness/.

9 Social recognition of traditional framings of expertise is normally predicated on output legitimacy, which prioritizes the production of valuable knowledge over the enforcement of the checks and balances required to minimize the impact of biases and vested interests in the construction of scientists' authoritative evidence. By contrast, participatory approaches to the governance of expertise prioritize process legitimacy-i.e. creating an environment where experts' claims, recommendations and interests can be challenged and resisted, and other voices can become involved in the translation of evidence into policies at the earliest possible opportunity. This epistemic shift towards process legitimacy calls for a better understanding of the needs of non-academic research users, including policy-makers (Nutley et al., 2007, p. 63) and, more widely, charitable organizations, business, professionals and practitioners, and the general public.

10 The itemized list of the Science Defies Politics posts included in CSBC-CON is available at https://genealogiesofknowledge.net/credits/defyccc/.

11 The itemized list of the Climate Depot posts included in CSBC-CON is available at https://genealogiesofknowledge.net/credits/climate-depot/.

12 The synopsis available on the documentary's promotional website (https:// sonyclassics.com/merchantsofdoubt/) states that Merchants of Doubt aims to lift "the curtain on a secretive group of highly charismatic, silver-tongued pundits-for-hire who present themselves in the media as scientific authorities-yet have the contrary aim of spreading maximum confusion about well-studied public threats ranging from toxic chemicals to pharmaceuticals to climate change".

13 The Media Bias/Fact Check website, for example, places Climate Depot under the 'Conspiracy-Pseudoscience' category and rates this blog as a "strong Pseudoscience source based on promotion of human influenced climate denialism propaganda and the use of poor sources who have failed numerous fact checks" (https:// mediabiasfactcheck.com/climate-depot/).

14 Freedman's (2009) article in The Washington Post is a case in point.

15 The itemized list of the Union of Concerned Scientists posts included in CSBC-ACC is available at https://genealogiesofknowledge.net/credits/ucsusa/. 
16 The itemized list of the DeSmog UK posts included in CSBC-ACC is available at https://genealogiesofknowledge.net/credits/desmoguk/.

17 The Media Bias/Fact Check website rates DeSmog UK as "left biased based on its political stance regarding climate change", and presents it as "an excellent source for researching who is funding climate science denial" (https://mediabiasfactcheck.com/ desmog/).

18 Contractive dialogic structures have also been the focus of recent studies of reader comments posted in response to climate change blogs (Metcalfe, 2020).

19 The Metafacet tool (Sheehan and Luz, 2019; Luz and Sheehan, 2020) draws on concordances generated while conducting searches for lexical items such as 'bias' to generate visualizations that display the number of concordance lines associated with a particular facet of the metadata-in this case, specific blogs. The list of blogs displayed in the output of the Metafacet visualizations used in this study are vertically ordered by the frequency of the search word in each of these outlets. The figures in the $x$-axis state the number of occurrences in each of the listed outlets. For further details, see the relevant section of the Genealogies User Manual, available at http:// genealogiesofknowledge.net/software/manual/\#facets.

20 Only tokens that can be used as noun phrases or parts of noun phrases are considered in my analysis, as not all the proclaiming markers of intersubjectivity studied in this paper can be used as verbs.

21 Based on the concordance output generated following a specific lexical search (e.g. 'bias'), the Mosaic visualization (Luz and Sheehan, 2014) produces positional word statistics. The MI3 score, one of several available under Mosaic's 'Collocation Strength' operating mode, is calculated by cubing the observed frequency of a term co-occurring with the search word, dividing this by its expected frequency in the corpus (i.e. the frequency one would expect if no factor other than random chance were affecting the frequencies), and then taking the logarithm to the base 2 of the result. The higher the MI3 score, the stronger the significance of a collocational relationship. For further details on this and other scores are available at http:// genealogiesofknowledge.net/software/manual/\#mosaic.

22 The 'Collocation Strength (Local)' operating mode has been chosen here because, by presenting each column of the Mosaic in full height, it makes it easier for the reader to gain visual access to more of the collocates that the search node attracts. The 'Collocational Strength (Global)' view would have delivered a scaled representation of the collocates based on their statistical significance. The height of the Mosaic titles in the global view is directly proportional to the MI3 score for each collocation, which can make it more difficult to access some of the collocate tiles in printed Mosaic visualizations.

23 Each of the examples provided in this section features a concordance line within a wider fragment of the relevant online blog post. This expanded context can be retrieved by clicking on a concordance line and then pressing the 'Extract' button on the concordancer's interface.

\section{References}

Auer MR, Zhang Y, Lee P (2014) The potential of microblogs for the study of public perceptions of climate change. WIREs Clim Change 5:291-296

Australian Climate Madness (n.d.) About. https://australianclimatemadness.com/ about/. Accessed 22 Nov 2019.

Bachelard M (2011) Witches, god, climate change... It's a matter of belief. The Sydney Morning Herald, 23 October. https://www.smh.com.au/environment/ climate-change/witches-god-climate-change-its-a-matter-of-belief-201110221mdpq.html. Accessed 22 Nov 2019

Bakhtin MM (1981) The dialogic imagination (trans: Emerson C, Holquist M). University of Texas Press, Austin

Beck S, Borie M, Esguerra A, Chilvers J, Heubach K, Hulme M, Lidskog R, Lövbrand E, Marquard E, Miller C, Nadim T, Nesshöver C, Settele, Turnhout E, Vasileiadou E, Görg C (2014) Climate change and the assessment of expert knowledge: does the IPCC model need updating?'. Bridges 40. https:// ostaustria.org/bridges-magazine/item/8244-climate-change-and-theassessment-of-expert-knowledge-does-the-ipcc-model-need-updating Accessed 22 Nov 2019

Biber D (2006) Stance in spoken and written university registers. J Engl Acad Purp 5:97-116

Borghi M (n.d.) Text and data mining. Copyrightuser.org website. https://www. copyrightuser.org/understand/exceptions/text-data-mining/. Accessed 22 Nov 2019

Bremer S, Stiller-Reeve M, Blanchard A, Mamnun N, Nazning Z, Kariser M (2018) Co-producing 'post-normal' climate knowledge with communities in Northeast Bangladesh. Wea. Climate Soc 10(2):259-268

Brevini B, Lewis J (eds) (2018) Climate change and the media. Peter Lang, New York and Berlin

Carrozza C (2015) Democratizing expertise and environmental governance: different approaches to the politics of science and their relevance for policy analysis. J Environ Policy Plan 17(1):108-126

Caudill D S, Conley S N, Gorman M E, Weinel M (eds) (2019) Introduction. in: The Third Wave in Science and Technology Studies. Palgrave Macmillan, Cham, p 1-13
Chinn S, Sol Hart P, Soroka S (2020) Politicization and polarization in climate change news content, 1985-2017. Sci Commun 42(1):112-129

Climate Depot (2009) Climate Depot launch press release. https://www.climatedepot. com/2009/04/06/climate-depot-aims-to-redefine-global-warming-reporting/. Accessed 22 Nov 2019

Collins H, Evans R (2002) The third wave of science studies: studies of expertise and sxperience. Soc Stud Sci 32(2):235-296

Collins H, Evans R (2007) Rethinking expertise. University of Chicago Press, Chicago

Collins H, Evans R (2020) Studies of expertise and experience. A sociological perspective on expertise. In: Ward P, Schraagen JM, Gore J, Roth E (eds) The Oxford handbook of expertise. Oxford University Press, New York, pp. $85-102$

Cooke D (2018) Automakers turn to climate deniers in quest to lower fuel economy regulations. Union of Concerned Scientists, 19 March. Available to view at https://blog.ucsusa.org/dave-cooke/automakers-turn-to-climate-deniersin-quest-to-lower-fuel-economy-regulations

Dayrell C (2019) Discourses around climate change in Brazilian newspapers: 2003-2013. Discourse Commun 13(2):149-171

Dayrell C, Urry J (2015) Mediating climate politics: the surprising case of Brazil. Eur J Soc Theory 18(3):57-273

DeMelle B (2014) DeSmog UK launches to combat climate denial in Europe ahead of Paris climate talks. The Narwhal, 1 September. https://thenarwhal.ca/ desmog-uk-launched-combat-climate-denial-europe-ahead-paris-climatetalks/. Accessed 22 Nov 2019

DeSmog UK (n.d.) About us. https://www.desmog.co.uk/about-us. Accessed 22 Nov 2019

Diakopoulos N, Zhang A, Elgesem D, Salway A (2014) Identifying and analyzing moral evaluation frames in climate change blog discourse. In: Proceedings of the eighth international AAAI conference on weblogs and social media, pp. 583-586. https://www.aaai.org/ocs/index.php/ICWSM/ICWSM14/paper/download/8064/ 8085. Accessed 22 Nov 2019

Douglas H (2009) Science, policy and the value-free ideal. University of Pittsburgh Press, Pittsburgh

Epstein S (1995) The construction of lay expertise: AIDS activism and the forging of credibility in the reform of clinical trials. Sci Technol Hum Values 20 (4):408-437

Farrell H, Drezner DW (2008) The power and politics of blogs. Public Choice 134:15-30

Farand C, Hope M (2018) Matthew and Sarah Elliott: How a UK power couple links US libertarians and fossil fuel lobbyists to Brexit. DeSmog UK, 19 November. Available to view at https://www.desmog.co.uk/2018/11/18/ matthew-sarah-elliott-uk-power-couple-linking-us-libertarians-and-fossilfuel-lobbyists-brexit

Feldman L, Sol Hart P, Milosevic T (2015) Polarizing news? Representations of threat and efficacy in leading US newspapers' coverage of climate change. Public Underst Sci 26(4):481-497

Fischer F (2009) Democracy and expertise: reorienting policy inquiry. Oxford University Press, Oxford

Fløttum K (2017) Language and climate change. In: Fløttum K (ed.) The role of language in the climate change debate. Routledge, London and New York, pp. $1-9$

Foucault M (1980) Two lectures. Power/knowledge. Random House, New York and Toronto, pp. $78-108$

Freedman A (2009) Obama needs to give a climate speech-ASAP. The Washington Post, 1 September. http://voices.washingtonpost.com/capitalweathergang/2009/ 09/obama needs_to_give_a_climate.html. Accessed 22 Nov 2019

Funtowicz SO, Ravetz JR (1991) A new scientific methodology for global environmental issues. In: Costanza R (ed.) Ecological economics: the science and management of sustainability. Columbia University Press, New York, pp. 137-152

Funtowicz SO, Ravetz JR (1992) Three types of risk assessment and the emergence of post-normal science. In: Krimsky S, Golding D (eds) Social theories of risk. Greenwood, Westport, pp. 251-273

Funtowicz SO, Ravetz JR (1993) Science for the post-normal age. Futures 25 (7):739-755

Gluckman P (2014) Brokering knowledge: giving science advice to government. Public Sector July/August(4). https://search.informit.com.au/documentSummary; $\mathrm{dn}=510236468569156$; res=IELBUS. Accessed 22 Nov 2019

Goldstein L (2015) Cult of climate change. Science Defies Politics. Available to view at https://defyccc.com/cult-of-climate-change/

Goldstein L (2017a) Seeing the world through the matrix and accidental AI? Science Defies Politics, 16 August. Available to view at https://defyccc.com/ one-nation-under-accidental-artificial-intelligence/

Goldstein L (2017b) Google anti-conservative bias unchanged since 2015. Australian Climate Madness, 30 September. Available to view at https://defyccc com/google-anti-conservative-bias-unchanged-since-2015/

Gunther A (2018) Rep. Lamar Smith misunderstands science. Union of Concerned Scientists, 16 March. Available to view at https://blog.ucsusa.org/guestcommentary/rep-lamar-smith-misunderstands-science 
Hope M (2018) Climate science deniers' favourite journal just got 'overhauled" and it could lead to a skeptic shutout. DeSmog UK, 23 February. Available to view at https://www.desmog.co.uk/2018/02/23/climate-science-deniers-favouritejournal-just-got-overhauled-and-it-could-lead-skeptic-shutout

Howarth C, Sharman A (2015) Labeling opinions in the climate debate: a critical review. WIREs Clim Change 6:239-254

Hulme M (2017) Foreword. In: Fløttum K (ed.) The role of language in the climate change debate. Routledge, London and New York, pp. ix-xii

IPCC (n.d.) The Intergovernmental Panel on Climate Change. https://www.ipcc. ch/. Accessed 22 Nov 2019

Jasanoff S (1999) STS and public policy. Getting beyond deconstruction. Sci Technol Soc 4(1):59-72

Jasanoff S (2003) (No?) Accounting for expertise. Sci Public Policy 30(3):157-162 Jasanoff S (2010) A new climate for society. Theory Cult Soc 27(2-3):233-253

Jasanoff S, Wynne B (1998) Science and decision making. In: Rayner S, Malone EL (ed) Human choice and climate change. Batelle Press, Columbus, pp. 1-87

Kahan D, Peters E, Cantrell Dawson E, Slovic P (2017) Motivated numeracy and enlightened self-government. Behav Public Policy 1(1):54-86

Kenner R (2014) Merchants of doubt. IMDb entry. https://www.imdb.com/title/ tt3675568/. Accessed 22 Nov 2019

Kirby A (2018) Global warming did not pause. Desmog, 19 December. Available to view at https://www.desmog.co.uk/2018/12/19/global-warming-did-not-pause-study

Lörcher I, Taddicken M (2017) Discussing climate change online. Topics and perceptions in online climate change communication in different onlinepublic arenas. J Sci Commun 16(02):A03

Luz S, Sheehan S (2014) A graph based abstraction of textual concordances and two renderings for their interactive visualisation'. In: Proceedings of the 2014 international working conference on advanced visual interfaces. ACM, New York, pp. 293-296

Luz S, Sheehan S (2020) Methods and visualization tools for the analysis of medical, political and scientific concepts in genealogies of knowledge. Palgrave Commun 6, article 49. https://www.nature.com/articles/s41599-0200423-6

Mandel K (2016) The top 10 climate change articles in The Times, debunked. DeSmog UK, 24 April. Available to view at https://www.desmog.co.uk/2016/ 04/24/top-10-climate-change-articles-times-debunked

Martin JR, White PR (2005) The language of evaluation. Appraisal in English. Palgrave Macmillan, Basingstoke and New York

Mathiesen K (2017) Climate change 'probably doing good', says former Australian Prime Minister Tony Abbott. DeSmog UK, 9 October. Available to view at https://www.desmog.co.uk/2017/10/09/climate-change-probably-doinggood-says-former-australian-prime-minister-tony-abbott

Mathiesen K (2018) Brazil's new foreign minister is a climate science denier. DeSmog UK, 15 November. Available to view at https://www.desmog.co.uk/ 2018/11/15/brazil-s-new-foreign-minister-climate-science-denier

Merchants of Doubt Trailer (2015) Merchants of doubt official trailer 1 (2014) documentary HD. https://www.youtube.com/watch?v=j8ii9zGFDtc. Accessed 22 Nov 2019

Metcalfe J (2020) Chanting to the choir: the dialogical failure of antithetical climate change blogs. J Sci Commun 19(02):A04

Meyer R (2016) Are climate scientists ready for Trump? Maybe not. The Atlantic, 27 December. https://www.theatlantic.com/science/archive/2016/12/areclimate-scientists-ready-for-trump/511604/. Accessed 22 Nov 2019

Moser SC (2016) Reflections on climate change communication research and practice in the second decade of the 21st century: what more is there to say? WIREs Clim Change 7(3):345-369

Newman TP, Nisbet EC, Nisbet MC (2018) Climate change, cultural cognition, and media effects: worldviews drive news selectivity, biased processing, and polarized attitudes. Public Underst Sci 27(8):985-1002

Nisbet MC, Markowitz EM (2015) Expertise in an age of polarization: evaluating scientists' political awareness and communication behaviors. Ann Am Acad Political Soc Sci 658:136-154

Nutley S, Walter I, Davies H (2007) Using evidence: how research can inform public services. Policy Press, Bristol

O'Neill S, Williams HP, Kurz T, Wiersma B, Boykoff M (2015) Dominant frames in legacy and social media coverage of the IPCC fifth assessment report. Nat Climate Change 5:380-385

Oppenheimer M, Oreskes N, Jamieson D, Brysse K, O'Reilly J, Shindell M, Wazeck M (2019) Discerning experts. The practices of scientific assessment for environmental policy. The University of Chicago Press, Chicago

Poliakoff E, Webb TL (2007) What factors predict scientists' intentions to participate in public engagement of science activities? Sci Commun 29:242-263

Rip A (2003) Constructing expertise: In a third wave of science studies? Soc Stud Sci 33(3):419-434

Salway A (2017) Data-driven approaches to climate change discourse, illustrated through case studies of blogs and international climate negotiation. In: Fløttum K (ed.) The role of language in the climate change debate. Routledge, London and New York, pp. 151-170
Salway A, Elgesem D, Hofland K, Reigem Ø, Steskal L (2016) Topically-focused blog corpora for multiple languages. In: Proceedings of the 10th web as corpus workshop (WAC-X), ACT 2016. https://www.aclweb.org/anthology/ W16-2603/. Accessed 22 Nov 2019

Schäfer M (2012) Online communication on climate change and climate politics: a literature review'. WIREs Climate Change 3:527-543

Schoonover R (2019) The White House blocked my report on climate change and national security. NY Times 30 July. https://www.nytimes.com/2019/07/30/ opinion/trump-climate-change.html. Accessed 22 Nov 2019

Science Defies Politics (n.d.) About. https://defyccc.com/about/. Accessed 22 Nov 2019

Shapin S (1995) Here and everywhere: sociology of scientific knowledge. Annu Rev Sociol 21:289-321

Sharman A (2015) The impact of controversy on the production of scientific knowledge. Centre for Climate Change Economics And Policy working paper no. 233. http://www.lse.ac.uk/GranthamInstitute/wp-content/uploads/2015/ 09/Working-Paper-207-Sharman.pdf. Accessed 22 Nov 2019

Sheehan S, Luz S (2019) Text visualization for the support of lexicography-based scholarly work. In: Proceedings of eLex 2019. https://elex.link/elex2019/wpcontent/uploads/2019/09/eLex_2019_40.pdf. Accessed 22 Nov 2019

Spanger-Siegfried E (2016) Lies hurt. Facts matter. And so does resistance. Union of Concerned Scientists, 12 December. Available to view at https://blog. ucsusa.org/erika-spanger-siegfried/lies-hurt-facts-matter-and-so-doesresistance

Tabuchi H (2017) How climate change deniers rise to the top in Google searches. NY Times, 29 December. https://www.nytimes.com/2017/12/29/climate/ google-search-climate-change.html. Accessed 22 Nov 2019

Tangney P (2017) Climate adaptation policy and evidence: understanding the tensions between politics and expertise in public policy. Routledge-Earthscan, London

Tangney P (2019a) Between conflation and denial-the politics of climate expertise in Australia. Aust J Political Sci 54(1):131-149

Tangney P (2019b) Does risk-based decision-making present an 'epistemic trap' for climate change policymaking? Evid Policy. https://doi.org/10.1332/ 174426419X1557747600211

Thompson G, Hunston S (2000) Evaluation: an introduction. In: Hunston S, Thompson G (eds) Evaluation in text. Authorial stance and the construction of discourse. Oxford University Press, Oxford, pp. 1-27

Turner SP (2014) The politics of expertise. Routledge, London and New York

Turnill S (2009) Hilarious: Rudd enlists Galileo's 'help'. Australian Climate Madness, 19 November. Available to view at https://australianclimatemadness. com/2009/11/19/hilarious-rudd-enlists-galileos-help/

Turnill S (2010a) Christopher Booker on the IPCC. Australian Climate Madness, 6 September. Available to view at https://australianclimatemadness.com/2010/ 09/06/christopher-booker-on-the-ipcc/

Turnill S (2010b) IPCC quotes WWF (again) ... and gets it wrong (again). Australian Climate Madness, 13 March. Available to view at https:// australianclimatemadness.com/2010/03/13/ipcc-quotes-wwf-again-gets-itwrong-again/

Turnill S (2011) Yet more bad science. Australian Climate Madness, 29 September. Available to view at https://australianclimatemadness.com/2011/09/29/usyet-more-bad-science/

Turnill S (2012) ABC: institutionalised bias. Australian Climate Madness, 26 November. Available to view at https://australianclimatemadness.com/2012/ 11/26/abc-institutionalised-bias/

Union of Concerned Scientists (n.d.) Who we are. https://www.ucsusa.org/about. Accessed 22 Nov 2019

Van Rensburg W (2015) Scepticism about anthropogenic climate disruption: a conceptual exploration. Unpublished doctoral thesis, The University of Queensland. https://core.ac.uk/download/pdf/43380080.pdf. Accessed 22 Nov 2019

Waldman S (2019) Trump officials deleting mentions of 'climate change' from U.S. Geological survey press releases. Science. https://www.sciencemag.org/news/ 2019/07/trump-officials-deleting-mentions-climate-change-us-geologicalsurvey-press-releases. Accessed 22 Nov 2019

Walter S, Lörcher I, Brüggemann M (2019) Scientific networks on Twitter: analyzing scientists' interactions in the climate change debate. Public Underst Sci 28(6):696-712

Wynne B (1989) Sheep farming after Chernobyl: a case study in communicating scientific information. Environment 31(2):10-39

Wynne B (2003) Seasick on the Third Wave: subverting the hegemony of propositionalism. Soc Stud Sci 33(3):401-417

Wynne B (2006) Public engagement as a means of restoring public trust in science -hitting the notes, but missing the music. Community Genet 9(3):211-220

Wynne B (2016) Ghosts in the machine: publics, meanings and a social science in a time of expert dogma in denial. In: Chilvers J, Kearnes M (eds) Remaking participation: science, environment and emergent public. Routledge, London and New York, pp. 99-120 


\section{Acknowledgements}

This research was supported by the Arts and Humanities Research Council, UK (Grant number: AH/M010007/1)

\section{Competing interests}

The author declares no competing interests.

\section{Additional information}

Correspondence and requests for materials should be addressed to L.P.-G.

Reprints and permission information is available at http://www.nature.com/reprints

Publisher's note Springer Nature remains neutral with regard to jurisdictional claims in published maps and institutional affiliations. (c) (i) Open Access This article is licensed under a Creative Commons Attribution 4.0 International License, which permits use, sharing, adaptation, distribution and reproduction in any medium or format, as long as you give appropriate credit to the original author(s) and the source, provide a link to the Creative Commons license, and indicate if changes were made. The images or other third party material in this article are included in the article's Creative Commons license, unless indicated otherwise in a credit line to the material. If material is not included in the article's Creative Commons license and your intended use is not permitted by statutory regulation or exceeds the permitted use, you will need to obtain permission directly from the copyright holder. To view a copy of this license, visit http://creativecommons.org/ licenses/by/4.0/.

(C) The Author(s) 2020 